\title{
Level of Thyroid-Stimulating Hormone (TSH) in Patients with Acute Schizophrenia, Unipolar Depression or Bipolar Disorder
}

\author{
Adam Wysokiński • Iwona Kłoszewska
}

Received: 2 March 2014/Revised: 1 April 2014/Accepted: 4 April 2014/Published online: 11 April 2014

(C) The Author(s) 2014. This article is published with open access at Springerlink.com

\begin{abstract}
The aim of this study is to investigate differences in thyroid-stimulating hormone (TSH) level in patients with acute schizophrenia, unipolar depression, bipolar depression and bipolar mania. Serum level of TSH was measured in 1,685 Caucasian patients (1,064 women, $63.1 \%$; mean age 46.4). Mean serum TSH concentration was: schizophrenia $(\mathrm{n}=769) \quad 1.71 \mu \mathrm{IU} / \mathrm{mL}$, unipolar depression $(\mathrm{n}=651) \quad 1.63 \mu \mathrm{IU} / \mathrm{mL}$, bipolar disorder $(\mathrm{n}=264) \quad 1.86 \mu \mathrm{IU} / \mathrm{mL}$, bipolar depression $(\mathrm{n}=203)$ $2.00 \mu \mathrm{IU} / \mathrm{mL}$, bipolar mania $(\mathrm{n}=61) \quad 1.38 \mu \mathrm{IU} / \mathrm{mL}$ ( $\mathrm{H}=11.58, p=0.009)$. Depending on the normal range used, the overall rate of being above or below the normal range was $7.9-22.3 \%$ for schizophrenia, $13.9-26.0 \%$ for unipolar depression, 10.8-27.6\% for bipolar disorder, $12.2-28.5 \%$ for bipolar depression, and $11.4-24.5 \%$ for bipolar mania. We have also found differences in TSH levels between the age groups $(\leq 20,>20$ years and $\leq 40$, $>40$ years and $\leq 60$ years and $>60$ years). TSH level was negatively correlated with age $(\mathrm{r}=-0.23, p<0.001)$. Weak correlations with age have been found in the schizophrenia $(\mathrm{r}=-0.21, p<0.001)$, unipolar depression $(\mathrm{r}=-0.23, p<0.001)$, bipolar depression $(\mathrm{r}=$ $-0.25, p=0.002)$ and bipolar disorder $(\mathrm{r}=-0.21$, $p=0.005$ ) groups. Our results confirm that there may be a higher prevalence of thyroid dysfunctions in patients with mood disorders (both unipolar and bipolar) and that these two diagnostic groups differ in terms of direction and frequency of thyroid dysfunctions.
\end{abstract}

\footnotetext{
A. Wysokiński $(\square) \cdot$ I. Kłoszewska

Department of Old Age Psychiatry and Psychotic Disorders,

Medical University of Lodz, Czechosłowacka 8/10,

92-216 Lodz, Poland

e-mail: adam.wysokinski@gmail.com
}

Keywords Thyroid-stimulating hormone . Schizophrenia - Depression - Bipolar disorder

\section{Introduction}

Thyroid-stimulating hormone (also known as thyrotropin, TSH) stimulates the thyroid gland to produce thyroxine (T4) and triiodothyronine (T3), which is a metabolismstimulating hormone. TSH is synthesized and secreted by thyrotrope cells in the anterior pituitary gland and regulates the endocrine function of the thyroid gland. Production and secretion of TSH is stimulated by the hypothalamus, which produces thyrotropin-releasing hormone (TRH). Production of TSH is inhibited by somatostatin, which is also produced by the hypothalamus, and via a negative feedback loop by T3 and T4 [1].

Schizophrenia, bipolar disorder and unipolar depression are the most severe psychiatric disorders. They have high prevalence, chronic course, significant mental and somatic comorbidity and very high personal and societal costs (lost productivity and increased medical expenses). Also, many patients respond poorly to medications and have frequent and disrupting relapses. Finally, although several biological markers have been identified, such as cortisol [2] or brain derived neurotrophic factor (BDNF) [3], none of them is conclusive, partly because they are shared by different disorders. This results mainly from complex mechanisms underlying development of these disorders. TSH also cannot be used as a single biomarker of any mental disorder, but could serve as an additional biomarker for improving diagnostic or therapeutic procedures.

The relation between thyroid function and mental disorders has long been recognized. Thyroid disorders, including both hypothyroidism and hyperthyroidism, may 
be accompanied by various neuropsychiatric manifestations, ranging from depression [4] and anxiety [5] to psychosis [6]. Hypothyroidism clinical symptoms may mimic melancholic depression and dementia, while in elderly patients hyperthyroidism may mimic depression and pseudodementia [7]. Also, TSH levels are correlated with depression severity [8] and hyperthyroidism may increase the risk of developing bipolar disorders [9]. Placidi et al. [10] have found higher rates of panic disorder, simple phobia, obsessive-compulsive disorder, major depressive disorder, bipolar disorder and cyclothymia in thyroid patients than in the general population. These findings would suggest that the co-occurrence of psychiatric and thyroid diseases may be the result of common biochemical abnormalities. Association between thyroid function and mood disorders are particularly important in elderly patients. Chueire et al. [11] reported that depression was observed more frequently among individuals with subclinical $(49.7 \%)$ hypothyroidism than among individuals with overt hypothyroidism $(16.8 \%)(p<0.001)$ and subclinical hypothyroidism increased the risk for a patient to present depression more than four times $(\mathrm{OR}=4.9)$. In schizophrenia results of thyroid function studies are inconclusive. Rinieris et al. [12] found that antipsychotics may affect serum thyroid hormones levels. Rao et al. [13] concluded that increased dopaminergic activity affects pituitary secretory functions and may lead to reduced TSH levels. Subclinical hypothyroidism may be present in treatment-naive patients with schizophrenia and treatment with antipsychotics may increase basal TSH levels [14], while Rao et al. [15] found no difference between treated and untreated patients. Higher basal TSH levels may be associated with a poorer treatment response in schizophrenia [16], while T4 levels showed a positive correlation with the severity of illness and the degree of clinical response to neuroleptic treatment [17].

The above findings would suggest that the co-occurrence of psychiatric and thyroid diseases may be the result of common biochemical abnormalities. Therefore, we have carried out this study in order to investigate differences in TSH level in patients with schizophrenia, unipolar depression, bipolar depression and bipolar mania.

\section{Methods}

This was a retrospective, cross-sectional, naturalistic study. Our psychiatry clinical hospital database was screened for serum thyroid-stimulating hormone (TSH) level. Only the first entry for each patient from inpatient care units were used for analysis. Usually the first blood tests are done next day after admission to our units. Thus, we have assumed that most patients that we included in the study were in acute phase of their disorder. We focused on patients with schizophrenia (all subtypes), bipolar disorder and unipolar depression. Patients of all ages were included in the study.

Results for 1,685 Caucasian patients were included in the study. Patients were grouped under diagnostic criteria as schizophrenia (F20 according to ICD-10, 295 according to DSM-IV), unipolar depression (F31 and F32 according to ICD-10, 296.2 and 296.3 according to DSM-IV), bipolar disorder (F30 and F31 according to ICD-10, 296.[0,4,6] according to DSM-IV), bipolar depression (F31.3-F31.5 according to ICD-10, 296.6 according to DSM-IV) and bipolar mania (F30 and F31.0-F31.2 according to ICD-10, 296.0 and 296.4 according to DSM-IV). In our unit diagnosis is based on the ICD-10 criteria, DSM-IV codes were given as reference.

Blood samples were drawn for all patients between 8 and 9 a.m. after $12 \mathrm{~h}$ overnight fast. Immediately after collecting blood samples TSH serum level was determined using automatic analyzer Dirui CS-400 (Dirui, China). For the normal range three different criteria were used: (1) the currently accepted $0.4-5.0 \mu \mathrm{IU} / \mathrm{mL}$ range; (2) the $0.3-3.0 \mu \mathrm{IU} / \mathrm{mL}$ range proposed by the American Association of Clinical Endocrinology [18]; and (3) the $0.4-2.5 \mu \mathrm{IU} / \mathrm{mL}$ range recommended by The National Academy of Clinical Biochemistry (NACB) [19].

Statistical procedures were performed with STATA 13.1 (StataCorp, USA). Simple descriptive statistics (means and standard deviations) were generated for continuous variables. For discrete variables number of patients and percentages are given. Normality of distribution was tested with Shapiro-Wilk test. TSH level did not follow normal distribution, even after transformation of this variable. Inter-group differences were analyzed using KruskalWallis test (for TSH level) or one-way ANOVA (for age), intra-group differences were analyzed using Wilcoxon rank-sum test. The difference between proportions was analyzed with the Chi square test. Associations were tested by Spearman's correlation coefficient. The significant level was set at $p<0.05$.

\section{Results}

Ine the study group of 1,685 patients included in the analysis there were $63.1 \%$ women $(\mathrm{n}=1,064)$. The proportion of women in the schizophrenia group $(\mathrm{n}=769)$ was $50.5 \%(\mathrm{n}=388)$, in the unipolar depression group $(\mathrm{n}=652)$ was $75.8 \%(\mathrm{n}=494)$, in the bipolar disorder group $(\mathrm{n}=264)$ was $68.9 \%(\mathrm{n}=182)$, in the bipolar depression group $(\mathrm{n}=203)$ was $71.9 \%(\mathrm{n}=146)$ and in the bipolar mania $(n=61)$ was $59.0 \%(n=36)$. The difference between the groups in the proportion of women was significant $\left(\chi^{2}=105.01, d f=3, p<0.001\right)$, with the 


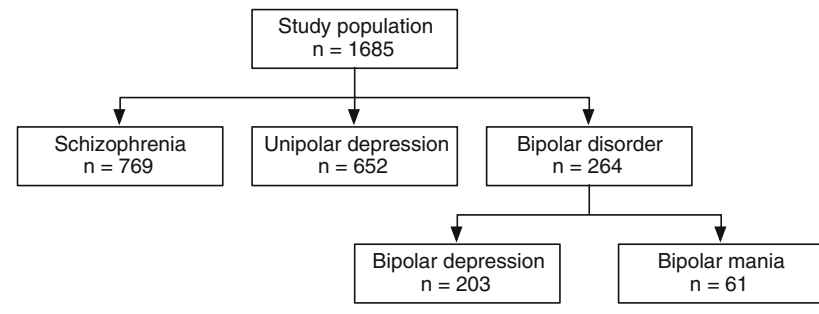

Fig. 1 Total number of patients and stratification of patients into diagnostic groups

Table 1 Age distribution in the study sample

\begin{tabular}{lccccl}
\hline Diagnosis & \multicolumn{2}{l}{ Age category } & & & Total [n (\%)] \\
\cline { 2 - 4 } & $<20$ & $20-40$ & $40-60$ & $>60$ & \\
\hline Schizophrenia & & & & & \\
Men & 26 & 248 & 76 & 31 & $381(49.5)$ \\
Women & 31 & 172 & 115 & 70 & $388(50.5)$ \\
Total & 57 & 420 & 191 & 101 & 769 \\
Unipolar depression & & & & \\
Men & 24 & 20 & 57 & 57 & $158(24.2)$ \\
Women & 93 & 34 & 165 & 202 & $494(75.8)$ \\
Total & 117 & 54 & 222 & 259 & 652 \\
Bipolar disorder & & & & \\
Men & 11 & 24 & 21 & 26 & $82(31.1)$ \\
Women & 8 & 43 & 61 & 70 & $182(68.9)$ \\
Total & 19 & 67 & 82 & 96 & 264 \\
Bipolar depression & & & & \\
Men & 5 & 16 & 12 & 24 & $57(28.1)$ \\
Women & 4 & 35 & 50 & 57 & $146(71.9)$ \\
Total & 9 & 51 & 62 & 81 & 203 \\
Bipolar mania & & & & & \\
Men & 6 & 8 & 9 & 2 & $25(41.0)$ \\
Women & 4 & 8 & 11 & 13 & $36(59.0)$ \\
Total & 10 & 16 & 20 & 15 & 61 \\
\hline
\end{tabular}

lowest proportion of women in the schizophrenia group. In the schizophrenia group $(\mathrm{n}=769)$ there were three patients with hebephrenic subtype, 20 patients with paranoid schizophrenia and catatonic symptoms, four with residual schizophrenia and two with simple-type schizophrenia. These subgroups were to small to include them into separate analysis and therefore we decided to combine all patients with schizophrenia into one group. Figure 1 shows the total number of patients and stratification of patients into diagnostic groups.

The age (mean \pm standard deviation) of the study group was $46.4 \pm 19.8$ years. Mean age in the subgroups was: schizophrenia $\quad 40.0 \pm 16.2$, unipolar depression $52.1 \pm 21.7$, bipolar depression $52.8 \pm 18.4$, bipolar
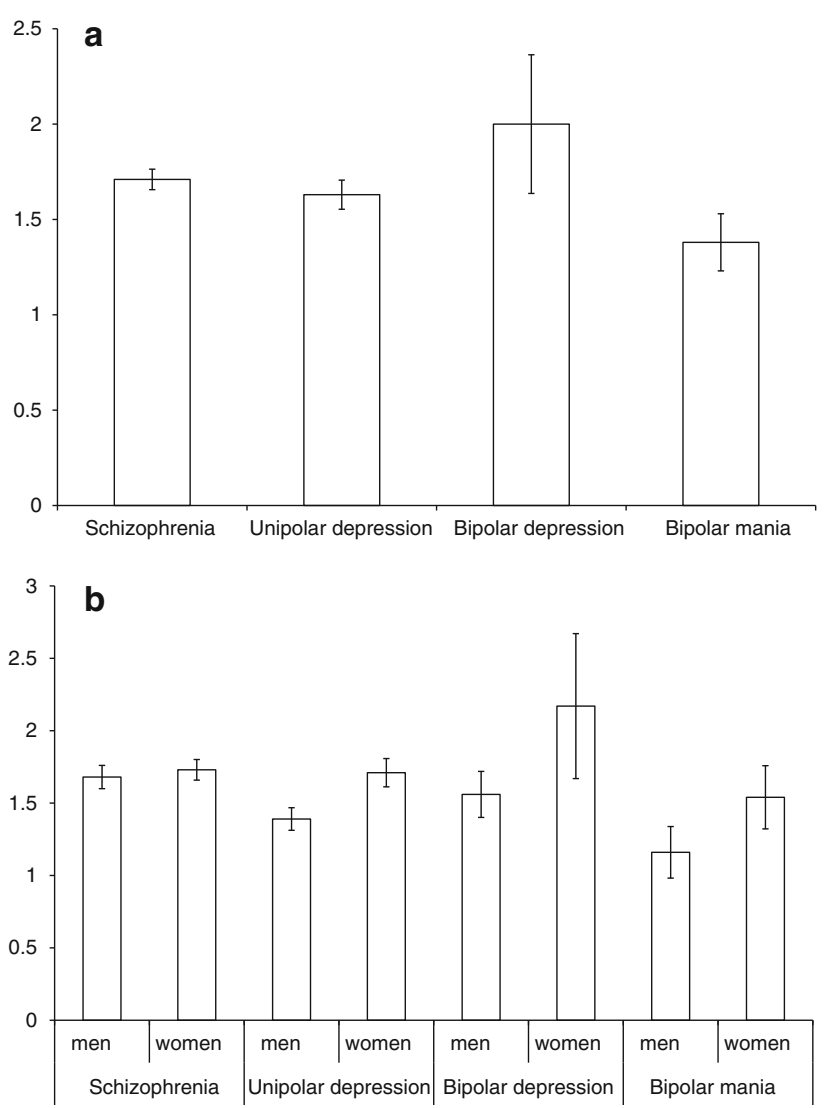

Fig. 2 Mean TSH levels $[\mu \mathrm{IU} / \mathrm{mL}]$ with standard error in subjects with schizophrenia, unipolar depression, bipolar depression and bipolar mania

mania $45.3 \pm 19.8$ years. One-way ANOVA showed that there were significant age differences between the groups $(\mathrm{F}=56.72, d f=3, p<0.001)$. Post hoc comparisons using the Bonferroni test showed that patients with unipolar- and bi-polar depression groups were significantly older ( $p<0.001$ for both groups). Age distribution in the study sample is shown in Table 1.

We have found several significant correlations between age and TSH level. In the whole study group TSH level was negatively correlated with age $(\mathrm{r}=-0.23$, $p<0.001)$, but not in the bipolar mania $(p=0.07)$ group. Weak correlations with age have been found in the schizophrenia $(\mathrm{r}=-0.21, p<0.001)$, unipolar depression $(\mathrm{r}=-0.23, p<0.001)$, bipolar depression $(\mathrm{r}=-0.25$, $p=0.002)$ and bipolar disorder $(\mathrm{r}=-0.21, p=0.005)$ groups.

For the whole study group there was no difference between men and women for TSH levels $(1.58 \pm 1.39$ vs. $1.77 \pm 2.82 \mu \mathrm{IU} / \mathrm{mL}, \mathrm{z}=-1.13, p=0.25)$. Mean serum TSH level in the study groups was: schizophrenia $1.71 \pm$ $1.49 \mu \mathrm{IU} / \mathrm{mL}$, unipolar depression $1.63 \pm 1.95 \mu \mathrm{IU} / \mathrm{mL}$, bipolar disorder group $1.86 \pm 4.58 \mu \mathrm{IU} / \mathrm{mL}$, bipolar 

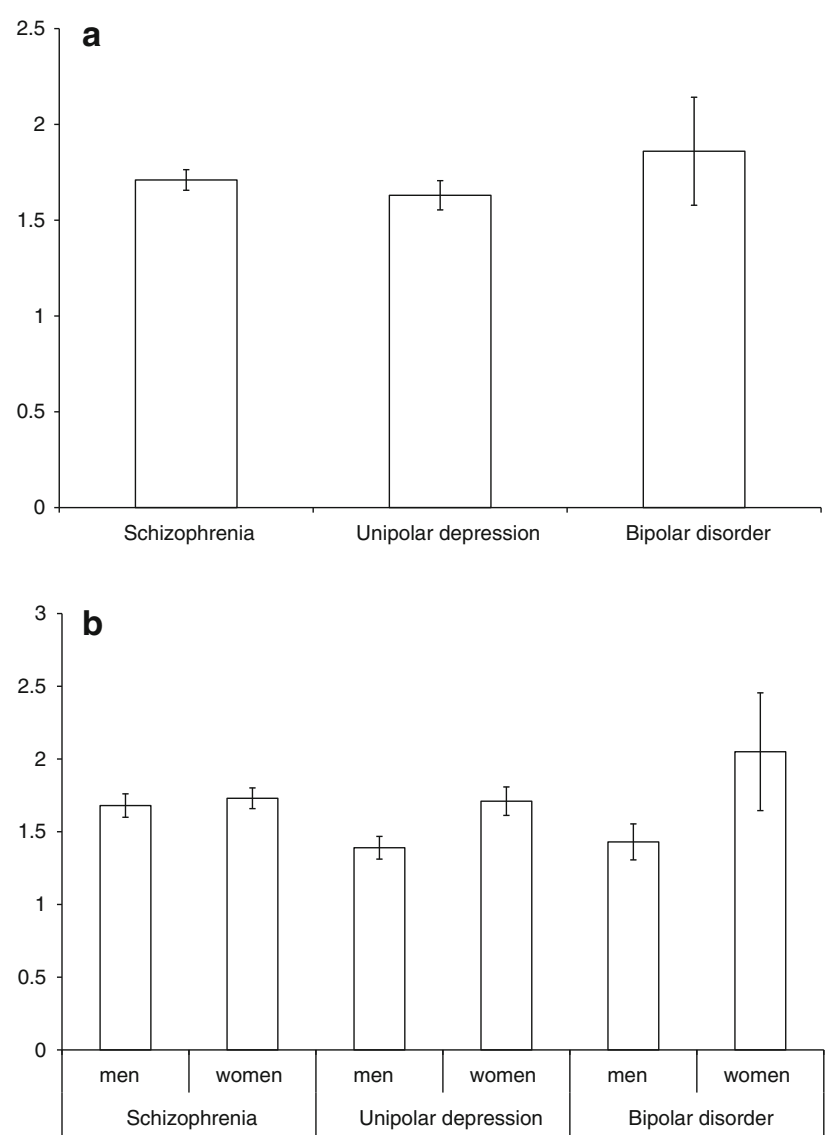

Fig. 3 Mean TSH levels $[\mu \mathrm{IU} / \mathrm{mL}]$ with standard error in subjects with schizophrenia, unipolar depression and bipolar disorder

depression $2.00 \pm 5.18 \mu \mathrm{IU} / \mathrm{mL}$, bipolar mania $1.38 \pm$ $1.17 \mu \mathrm{IU} / \mathrm{mL}$, see Fig. 2. There was a significant difference between the serum level of TSH between patients with schizophrenia, unipolar depression, bipolar depression and bipolar mania $(\mathrm{H}=11.58, d f=3, p=0.009)$. The highest level of TSH was found in the bipolar depression group $(2.00 \pm 5.18 \mu \mathrm{IU} / \mathrm{mL})$ and the lowest in patients with bipolar mania $(1.38 \pm 1.17 \mu \mathrm{IU} / \mathrm{mL})$. The difference was also significant for the subgroup of men $(\mathrm{H}=9.89, d f=3$, $p=0.019)$, but not for women $(\mathrm{H}=4.93, d f=3$, $p=0.17$ ). When patients with bipolar mania or depression were combined into one group (bipolar disorder), there were also significant inter-group differences between patients with schizophrenia, unipolar depression and bipolar disorder $(\mathrm{H}=8.62, d f=2, p=0.013)$. The lowest level was in patients with unipolar depression (1.63 \pm $1.95 \mu \mathrm{IU} / \mathrm{mL}$ ) and the highest level was in patients with bipolar disorder $(1.86 \pm 4.58 \mu \mathrm{IU} / \mathrm{mL})$, see Fig. 3 . The difference was also significant for the subgroup of men $(\mathrm{H}=7.49, \quad d f=2, \quad p=0.023$, but not for women $(\mathrm{H}=4.17, d f=2, p=0.12)$.

Table 2 shows sex distribution in diagnostic groups for normal ranges of TSH. Evaluation of the $0.4-5.0 \mu \mathrm{IU} / \mathrm{mL}$ normal range revealed significant differences between diagnostic groups with regard to serum TSH categories $\left(\chi^{2}=16.29, d f=6, p=0.012\right)$. When patients with bipolar depression and bipolar mania were combined into one group (bipolar disorder) the difference was also significant $\left(\chi^{2}=14.78, d f=4, p=0.005\right)$. The overall rate of being above or below the normal range was $7.9 \%$ for patients with schizophrenia, $13.9 \%$ for patients with unipolar depression, $10.8 \%$ for patients with bipolar disorder, $12.2 \%$ for patients with bipolar depression, and $11.4 \%$ for patients with bipolar mania. The rate of patients being below the normal range was the highest in patients with unipolar depression $(11.0 \%)$, while the rate of patients being above the normal range was the highest in patients with bipolar depression (4.4\%).With the exception of bipolar mania, the rate of patients being below or above the normal range was higher in women (where it was higher only in patients with TSH level above the normal range). However, statistical analysis revealed that in no group the difference was significant. There was a significant difference between age of patients with TSH level below or above normal range (below $56.3 \pm 17.6$ years, normal range $45.5 \pm 19.8$ years, above $48.2 \pm 19.8$ years, $\mathrm{F}=19.26, d f=2, p<0.001)$. Post hoc analysis showed that patients with TSH level below the normal range were significantly older comparing to patients with TSH level above $(p=0.042)$ or within the normal range $(p<0.001)$.

Evaluation of the $0.3-3.0 \mu \mathrm{IU} / \mathrm{mL}$ normal range revealed significant differences between diagnostic groups with regard to serum TSH categories $\left(\chi^{2}=15.55, d f=6\right.$, $p=0.016$ ). When patients with bipolar depression and bipolar mania were combined into one group (bipolar disorder) the difference was also significant $\left(\chi^{2}=14.45\right.$, $d f=4, p=0.006$ ). The overall rate of being above or below the normal range was $14.3 \%$ for patients with schizophrenia, $17.0 \%$ for patients with unipolar depression, $19.0 \%$ for patients with bipolar disorder, $20.2 \%$ for patients with bipolar depression, and $14.7 \%$ for patients with bipolar mania. The rate of patients being below the normal range was the highest in patients with unipolar depression $(7.2 \%)$, while the rate of patients being above the normal range was the highest in patients with bipolar depression (14.3\%).With the exception of bipolar mania, the rate of patients being below or above the normal range was higher in women (where it was higher only in patients with TSH level above the normal range). However, statistical analysis revealed that in no group the difference was significant. There was a significant difference between age of patients with TSH level below or above normal range (below $57.9 \pm 17.1$ years, normal range $46.1 \pm$ 19.8 years, above $43.7 \pm 19.3$ years, $\mathrm{F}=16.50, d f=2$, $p<0.001)$. Post hoc analysis showed that patients with TSH level below the normal range were significantly older 
Table 2 Sex distribution in diagnostic groups for normal ranges of TSH

\begin{tabular}{|c|c|c|c|c|c|c|c|c|c|}
\hline \multirow[t]{2}{*}{ Diagnosis } & \multicolumn{9}{|c|}{ TSH category $[(\mu \mathrm{IU} / \mathrm{mL}) \mathrm{n}(\%)]$} \\
\hline & $<0.4$ & $0.4-5.0$ & $>5.0$ & $<0.3$ & $0.3-3.0$ & $>3.0$ & $<0.4$ & $0.4-2.5$ & $>2.5$ \\
\hline Schizophrenia & $44(5.7)$ & $706(91.8)$ & $19(2.5)$ & $24(3.1)$ & $659(85.7)$ & $86(11.2)$ & $44(5.7)$ & 597 (77.6) & $128(16.6)$ \\
\hline Men & $20(5.2)$ & $354(92.9)$ & $7(1.8)$ & $8(2.1)$ & $331(86.9)$ & $42(11.0)$ & $20(5.2)$ & $300(78.7)$ & $61(16.0)$ \\
\hline Women & $24(6.2)$ & $352(90.7)$ & $12(3.1)$ & $16(4.1)$ & $328(84.5)$ & $44(11.3)$ & $24(6.2)$ & $297(76.5)$ & $67(17.3)$ \\
\hline Unipolar depression & $72(11.0)$ & $561(86.0)$ & $19(2.9)$ & $47(7.2)$ & $541(83.0)$ & $64(9.8)$ & $72(11.0)$ & $482(73.9)$ & $98(15.0)$ \\
\hline Men & $15(9.5)$ & $141(89.2)$ & $2(1.3)$ & $10(6.3)$ & $136(86.1)$ & $12(7.6)$ & $15(9.5)$ & $123(77.8)$ & $20(12.7)$ \\
\hline Women & $57(11.5)$ & $420(85.0)$ & $17(3.4)$ & $37(7.5)$ & $405(82.0)$ & $52(10.5)$ & $57(11.5)$ & 359 (72.7) & $78(15.8)$ \\
\hline Bipolar disorder & $22(8.3)$ & $232(87.9)$ & $19(2.5)$ & $15(5.7)$ & $214(81.1)$ & $35(13.3)$ & $22(8.3)$ & $191(72.3)$ & $51(19.3)$ \\
\hline Men & $6(7.3)$ & $74(90.2)$ & $7(1.8)$ & $3(3.7)$ & $72(87.8)$ & $7(8.5)$ & $6(7.3)$ & $64(78.0)$ & $12(14.6)$ \\
\hline Women & $16(8.8)$ & $158(86.8)$ & $12(3.1)$ & $12(6.6)$ & $142(78.0)$ & $28(15.4)$ & $16(8.8)$ & $127(69.8)$ & $39(21.4)$ \\
\hline Bipolar depression & $16(7.8)$ & $178(87.7)$ & $9(4.4)$ & $12(5.9)$ & $162(79.8)$ & $29(14.3)$ & $16(7.8)$ & 145 (71.4) & $42(20.7)$ \\
\hline Men & $2(3.51)$ & $53(93.0)$ & $2(3.5)$ & $1(1.7)$ & $50(87.7)$ & $6(10.5)$ & $2(3.51)$ & 45 (78.9) & $10(17.5)$ \\
\hline Women & $14(9.59)$ & $125(85.6)$ & $7(4.8)$ & $11(7.5)$ & $112(76.7)$ & $23(15.7)$ & $14(9.59)$ & $100(68.5)$ & $32(21.9)$ \\
\hline Bipolar mania & $6(9.8)$ & $54(88.5)$ & $1(1.6)$ & $3(4.9)$ & $52(85.2)$ & $6(9.8)$ & $6(9.8)$ & $46(75.4)$ & $9(14.7)$ \\
\hline Men & $4(16.0)$ & $21(84.0)$ & 0 & $2(8.0)$ & $22(88.0)$ & $1(4.0)$ & $4(16.0)$ & $19(76.0)$ & $2(8.0)$ \\
\hline Women & $2(5.6)$ & $33(91.7)$ & $1(2.8)$ & $1(2.8)$ & $30(83.3)$ & $5(13.9)$ & $2(5.6)$ & $27(75.0)$ & $7(19.4)$ \\
\hline
\end{tabular}

comparing to patients with TSH level above $(p<0.001)$ or within the normal range $(p<0.001)$.

Evaluation of the $0.4-2.5 \mu \mathrm{IU} / \mathrm{mL}$ normal range revealed significant differences between diagnostic groups with regard to serum TSH categories $\left(\chi^{2}=16.69, d f=6\right.$, $p=0.010)$. When patients with bipolar depression and bipolar mania were combined into one group (bipolar disorder) the difference was also significant $\left(\chi^{2}=15.36\right.$, $d f=4, p=0.004)$. The overall rate of being above or below the normal range was $22.3 \%$ for patients with schizophrenia, $26.0 \%$ for patients with unipolar depression, $27.6 \%$ for patients with bipolar disorder, $28.5 \%$ for patients with bipolar depression, and $24.5 \%$ for patients with bipolar mania. The rate of patients being below the normal range was the highest in patients with unipolar depression $(11.0 \%)$, while the rate of patients being above the normal range was the highest in patients with bipolar depression $(20.7 \%)$.With the exception of bipolar mania, the rate of patients being below or above the normal range was higher in women (where it was higher only in patients with TSH level above the normal range). However, statistical analysis revealed that in no group the difference was significant. There was a significant difference between age of patients with TSH level below or above normal range (below $56.3 \pm 17.6$ years, normal range $46.4 \pm$ 19.7 years, above $42.0 \pm 20.2$ years, $\mathrm{F}=24.58, d f=2$, $p<0.001$ ). Post hoc analysis showed that patients with TSH level below the normal range were significantly older comparing to patients with TSH level above $(p<0.001)$ or within the normal range $(p<0.001)$, while patients with TSH level above the normal range were younger than patients with TSH level within the normal range $(p=0.002)$.

We have also analyzed differences in TSH levels between the age groups. Patients were divided into four group: $\leq 20,>20$ years and $\leq 40,>40$ years and $\leq 60$ years and $>60$ years. Age distributions of TSH level are shown in Table 3 for patients with schizophrenia, in Table 4 for patients with unipolar depression, in Table 5 for patients with bipolar disorder, in Table 6 for patients with bipolar depression and in Table 7 for patients with bipolar mania. There were significant differences between TSH level in age groups of schizophrenia patients $(p<0.001)$, in men $(p<0.001)$ but not in women $(p=0.077)$. Comparing men with women, TSH level was higher in women only in the subgroup of patients aged 40-60 $(p=0.008)$, while other differences were not significant. In patients with unipolar depression there were significant differences between TSH level in age groups $(p<0.001)$, both in men $(p<0.001)$ and in women $(p<0.001)$. Comparing men with women, TSH level was higher in women only in the subgroup of patients aged $>60(p=0.002)$, while other differences were not significant. In patients with bipolar disorder there were significant differences between TSH level in age groups $(p=0.026)$, in women $(p=0.031)$ but not in men $(p=0.23)$. There were no differences in age groups between men and women with bipolar disorder. In patients with bipolar depression there were significant differences between TSH level in age groups $(p=0.014)$ but not in men $(p=0.06)$ and in women $(p=0.19)$. There were no differences in age groups between men and women with bipolar depression. In patients with bipolar 
Table 3 Mean TSH level (in $\mu \mathrm{IU} / \mathrm{mL}$ ) in patients with schizophrenia
† Inter age-subgroups, KruskalWallis test

* Men versus women, Wilcoxon rank-sum test

Table 4 Mean TSH level (in $\mu \mathrm{IU} / \mathrm{mL}$ ) in patients with unipolar depression

\begin{tabular}{|c|c|c|c|c|c|c|}
\hline & \multirow[t]{2}{*}{ Total } & \multicolumn{4}{|l|}{ Age category } & \multirow[t]{2}{*}{$p^{\dagger}$} \\
\hline & & $<20$ & $20-40$ & $40-60$ & $>60$ & \\
\hline Men & $1.68 \pm 1.57$ & $1.93 \pm 0.90$ & $1.75 \pm 1.32$ & $1.42 \pm 2.30$ & $1.64 \pm 1.72$ & $\begin{array}{l}\mathrm{H}=29.62 \\
p<0.001\end{array}$ \\
\hline Women & $1.73 \pm 1.40$ & $1.84 \pm 1.03$ & $1.81 \pm 1.36$ & $1.62 \pm 1.56$ & $1.63 \pm 1.38$ & $\begin{array}{l}\mathrm{H}=6.84 \\
p=0.077\end{array}$ \\
\hline Total & $1.71 \pm 1.49$ & $1.88 \pm 0.96$ & $1.77 \pm 1.33$ & $1.54 \pm 1.89$ & $1.63 \pm 1.48$ & $\begin{array}{l}\mathrm{H}=27.56 \\
p<0.001\end{array}$ \\
\hline$p^{*}$ & $\begin{array}{l}\mathrm{z}=-0.87 \\
p=0.38\end{array}$ & $\begin{array}{l}\mathrm{z}=0.68 \\
p=0.49\end{array}$ & $\begin{array}{l}\mathrm{z}=-0.57 \\
p=0.56\end{array}$ & $\begin{array}{l}\mathrm{z}=-2.66 \\
p=0.008\end{array}$ & $\begin{array}{l}\mathrm{z}=-0.42 \\
p=0.66\end{array}$ & \\
\hline
\end{tabular}

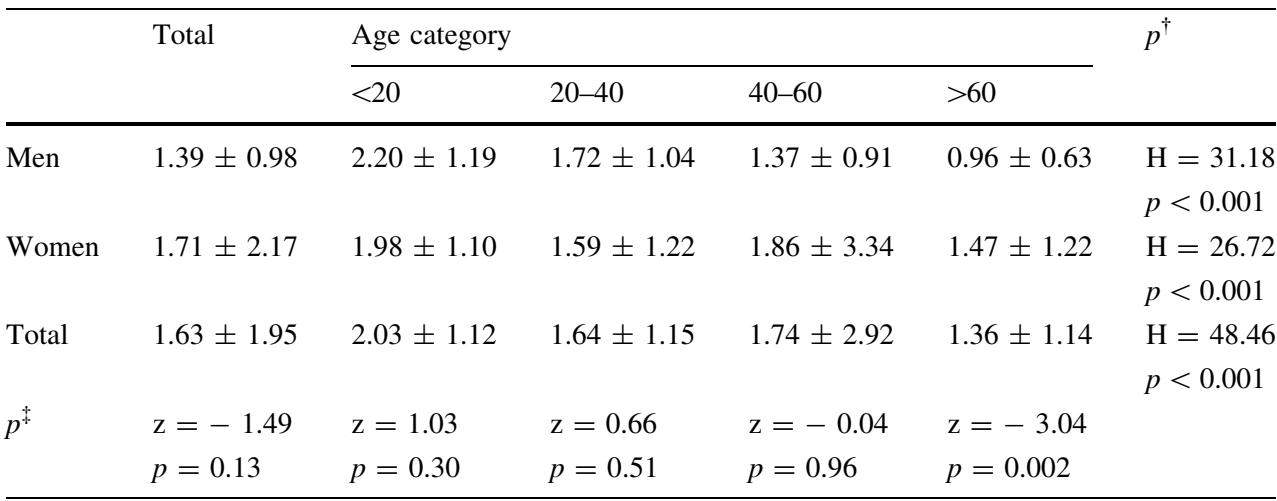

\begin{tabular}{lllllll}
\hline & Total & \multicolumn{2}{l}{ Age category } & $p^{\dagger}$ \\
\cline { 3 - 6 } & & $<20$ & $20-40$ & $40-60$ & $>60$ & \\
\hline Men & $1.43 \pm 1.12$ & $1.74 \pm 1.02$ & $1.53 \pm 1.36$ & $1.59 \pm 1.28$ & $1.09 \pm 0.70$ & $\begin{array}{l}\mathrm{H}=4.21 \\
p=0.23\end{array}$ \\
Women & $2.05 \pm 5.46$ & $2.73 \pm 2.28$ & $1.94 \pm 1.22$ & $1.49 \pm 1.37$ & $2.51 \pm 8.63$ & $\begin{array}{l}\mathrm{H}=8.87 \\
\end{array}$ \\
& & & & & & $p=0.031$ \\
Total & $1.86 \pm 4.58$ & $2.16 \pm 1.69$ & $1.80 \pm 1.27$ & $1.52 \pm 1.34$ & $2.13 \pm 7.39$ & $\mathrm{H}=9.28$ \\
& & & & & & $p=0.026$ \\
$p^{*}$ & $\mathrm{z}=-0.89$ & $\mathrm{z}=-0.57$ & $\mathrm{z}=-1.73$ & $\mathrm{z}=0.48$ & $\mathrm{z}=-0.86$ & \\
& $p=0.37$ & $p=0.56$ & $p=0.08$ & $p=0.62$ & $p=0.38$ & \\
\hline
\end{tabular}

Table 5 Mean TSH level (in $\mu \mathrm{IU} / \mathrm{mL}$ ) in patients with bipolar disorder $\dagger$ Inter age-subgroups, KruskalWallis test

* Men versus women, Wilcoxon rank-sum test depression and bipolar mania. We have analyzed TSH level in age subgroups of diagnostic groups, as well as distribution of results within and outside three different normal ranges.

We have found that patients with bipolar disorder have the highest level of TSH, while the lowest level was seen in patients with unipolar depression. When patients with bipolar mania and bipolar depression were analyzed as separate groups, we have found that patients with bipolar depression had the highest level of TSH, while the lowest level was found in patients with bipolar mania. This was also true of a subgroup of men, but not for women. This difference cannot be explained only by differences in age 
Table 6 Mean TSH level (in $\mu \mathrm{IU} / \mathrm{mL}$ ) in patients with bipolar depression

\begin{tabular}{|c|c|c|c|c|c|c|}
\hline & \multirow[t]{2}{*}{ Total } & \multicolumn{4}{|l|}{ Age category } & \multirow[t]{2}{*}{$p^{\dagger}$} \\
\hline & & $<20$ & $20-40$ & $40-60$ & $>60$ & \\
\hline Men & $1.56 \pm 1.20$ & $1.90 \pm 0.87$ & $1.84 \pm 1.47$ & $1.84 \pm 1.58$ & $1.15 \pm 0.69$ & $\begin{array}{l}\mathrm{H}=4.71 \\
p=0.19\end{array}$ \\
\hline Women & $2.17 \pm 6.05$ & $3.54 \pm 2.59$ & $1.93 \pm 1.27$ & $1.63 \pm 1.47$ & $2.71 \pm 9.54$ & $\begin{array}{l}\mathrm{H}=7.11 \\
p=0.06\end{array}$ \\
\hline Total & $2.00 \pm 5.18$ & $2.63 \pm 1.91$ & $1.90 \pm 1.32$ & $1.67 \pm 1.48$ & $2.25 \pm 8.02$ & $\begin{array}{l}\mathrm{H}=10.63 \\
p=0.014\end{array}$ \\
\hline$p^{*}$ & $\begin{array}{l}\mathrm{z}=-0.28 \\
p=0.77\end{array}$ & $\begin{array}{l}\mathrm{z}=-0.98 \\
p=0.32\end{array}$ & $\begin{array}{l}\mathrm{z}=-0.44 \\
p=0.65\end{array}$ & $\begin{array}{l}\mathrm{z}=0.39 \\
p=0.69\end{array}$ & $\begin{array}{l}\mathrm{z}=-0.45 \\
p=0.64\end{array}$ & \\
\hline
\end{tabular}

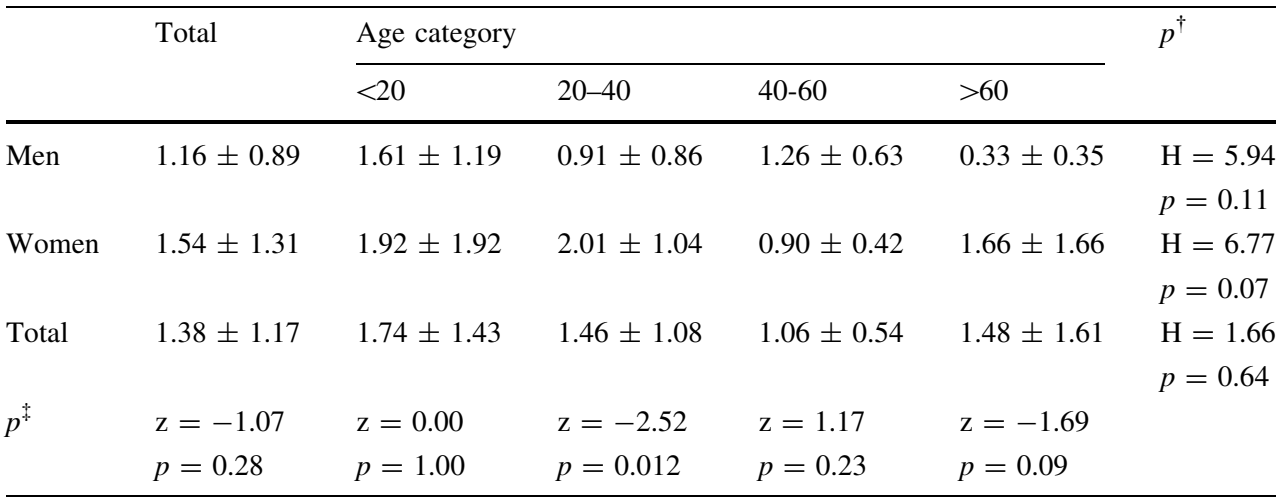

Table 7 Mean TSH level (in $\mu \mathrm{IU} / \mathrm{mL}$ ) in patients with bipolar mania
† Inter age-subgroups, KruskalWallis test

* Men versus women, Wilcoxon rank-sum test
Survey (NHANES) [20], where positive correlation between age and TSH level was found in a large $(\mathrm{n}=17,353)$ sample. This observation might be explained by the fact that our study sample has various potential risk factors of thyroid dysfunction, associated with clinical diagnosis and resulting from treatment. On the other hand, our results are consistent with results of the German study, which show that age was the only independent factor and was significantly inversely associated with TSH [21].

Meta-analysis of thyroid dysfunctions in Europe showed that the prevalence of undiagnosed hypothyroidism was $4.94 \%$ and the prevalence of undiagnosed hyperthyroidism was $1.72 \%$. The prevalence of both previously diagnosed and undiagnosed hypothyroidism and hyperthyroidism was 3.05 and $0.75 \%$, respectively [22]. For depression, $1-4 \%$ of patients are found to have overt hypothyroidism while subclinical hypothyroidism occurs in $4-40 \%$ of these patients [11]. In 868 elderly psychiatric long-term care patients $10.8 \%$ had elevated TSH, $8 \%$ in those with a prior diagnosis of hypothyroidism, while low TSH levels were found in $0.07 \%$ patients [23].

According to our data the prevalence of clinical and subclinical hypothyroidism in the study sample may be as high as 4.4-20.7\% (in patients with bipolar depression, for normal range $0.4-5.0$ and $0.4-2.5 \mu \mathrm{IU} / \mathrm{mL}$, respectively). As reported by Cole et al. patients with bipolar depression lation-based National Health and Nutrition Examination 
and with optimal thyroid profile experienced remission 4 months faster than the remainder of the study group. This study provides further evidence that patients with bipolar disorder are particularly sensitive to variations in thyroid function within the normal range and nearly three-quarters of patients with bipolar disorder have a thyroid profile that may be suboptimal for antidepressant response [24].

Regarding hyperthyroidism, the prevalence of clinical and subclinical hyperthyroidism in the study sample may be as high as $7.2-11.0 \%$ (in patients with unipolar depression, for normal range $0.3-3.0$ and $0.4-2.5$ or $0.4-5.0 \mu \mathrm{IU} / \mathrm{mL}$, respectively). The rate of low TSH in patients with bipolar disorder (TSH $<0.4 \mu \mathrm{IU} / \mathrm{mL}, 8.3 \%$ ) in this study was higher than previously reported $(6.2 \%)$ [25]. As noted by these authors, different definitions of hyperthyroidism are used in studies and direct comparisons are difficult.

Since we have no data on free T4 level, our interpretation of TSH level might be inaccurate and can be used only as rough estimations. Moreover, it should be noted that a state of "brain hypothyroidism" was reported in patients with depression [26]. This state of brain hypothyroidism occurs in systemic euthyroidism and may result from a defect of thyroid hormone receptor or impaired thyroid hormone transporter [27].

In the large NHANES study mean serum TSH was 1.50 $\mu \mathrm{IU} / \mathrm{mL}$ and was higher in females than males [20]. Comparing to this result, in our study sample mean serum TSH levels were higher in patients with schizophrenia $(1.71 \mu \mathrm{IU} /$ $\mathrm{mL})$, unipolar depression $(1.63 \mu \mathrm{IU} / \mathrm{mL})$, bipolar disorder $(1.86 \mu \mathrm{IU} / \mathrm{mL})$, bipolar depression $(2.00 \mu \mathrm{IU} / \mathrm{mL})$ and lower in patients with bipolar mania $(1.38 \mu \mathrm{IU} / \mathrm{mL})$. As above, this may also be explained by the fact that our study sample was not population-based and it reflects associations between mental disorders and thyroid dysfunctions.

In conclusion, our results confirm that there may be a higher prevalence of thyroid dysfunctions in patients with mood disorders (both unipolar and bipolar) and that these two diagnostic groups differ in terms of direction and frequency of thyroid dysfunctions. This also confirms the need to monitor TSH level regularly in patients with all types of mood disorders. When low normal TSH ranges are used (0.3-3.0 or 0.4$2.5 \mu \mathrm{IU} / \mathrm{mL}$ ), we could detect subclinical thyroid dysfunctions in higher number of highly susceptible patients (lowering the normal TSH range from 0.4-5.0 to 0.4-2.5 caused a five to eight-fold increase in the number of patients who had TSH levels outside the normal range). This is particularly important in the light of recommendations of the American Association of Clinical Endocrinologists, which state that "The diagnosis of subclinical hypothyroidism must be considered in every patient with depression" [18].

Our study has some limitations, which results mainly from its retrospective and naturalistic design. We have no clinical data, data for subtypes of bipolar disorder type I and II and rapid cycling. Diagnostic groups were based on diagnosis at discharge from the hospital, so it might be inaccurate in some cases, where strict diagnostic procedure using clinical criteria was not done. We only have data representing current medical condition and have no information regarding past thyroid disorders and their treatment. We also have no date on detailed thyroid assessment (T3, T4, anti-thyroid autoantibodies, results of ultrasonograph examinations). Diagnostic groups of our study were not homogenous, there were less women in the schizophrenia group comparing to other groups, while patients with unipolar and bipolar depression were significantly older comparing to other groups. Also, the bipolar disorder group was smaller comparing to schizophrenia and unipolar disorder (this is particularly true for bipolar mania group). These factors may affect results of inter- and intra-group comparisons. In case of patients with bipolar disorder we cannot exclude the effect of treatment with lithium on TSH level. Lithium may cause hypothyroidism, it was also reported that anti-depressants [28] as well as haloperidol [29] may affect thyroid functions and we have no detailed data on treatment that could be included in the analysis. On the other hand, the large sample size and ability to compare three major clinical groups (schizophrenia, unipolar depression and bipolar disorder) are strengths of the study.

Acknowledgments Publication supported within the framework of Healthy Ageing Research Centre (REGPOT-2012-2013-1, 7FP).

Conflict of interest None to declare.

Open Access This article is distributed under the terms of the Creative Commons Attribution License which permits any use, distribution, and reproduction in any medium, provided the original author(s) and the source are credited.

\section{References}

1. Larsen PR, Silva JE, Kaplan MM (1981) Relationships between circulating and intracellular thyroid hormones: physiological and clinical implications. Endocr Rev 2:87-102

2. Carroll BJ, Cassidy F, Naftolowitz D et al (2007) Pathophysiology of hypercortisolism in depression. Acta Psychiatr Scand 115(Suppl 433):90-103

3. Green MJ, Matheson SL, Shepherd A, Weickert CS, Carr VJ (2011) Brain-derived neurotrophic factor levels in schizophrenia: a systematic review with meta-analysis. Mol Psychiatry 16:960-972

4. Trzepacz PT, McCue M, Klein I, Levey GS, Greenhouse J (1988) A psychiatric and neuropsychological study of patients with untreated Graves' disease. Gen Hosp Psychiatry 10:49-55

5. Kathol RG, Delahunt JW (1986) The relationship of anxiety and depression to symptoms of hyperthyroidism using operational criteria. Gen Hosp Psychiatry 8:23-28

6. Snabboon T, Khemkha A, Chaiyaumporn C, Lalitanantpong D, Sridama V (2009) Psychosis as the first presentation of hyperthyroidism. Intern Emerg Med 4:359-360 
7. Hage MP, Azar ST (2012) The link between thyroid function and depression. J Thyroid Res 2012:590648

8. Bauer M, Goetz T, Glenn T, Whybrow PC (2008) The thyroidbrain interaction in thyroid disorders and mood disorders. J Neuroendocrinol 20:1101-1114

9. Hu LY, Shen CC, Hu YW et al (2013) Hyperthyroidism and risk for bipolar disorders: a nationwide population-based study. PLoS One 8:e73057

10. Placidi GP, Boldrini M, Patronelli A, Fiore E, Chiovato L, Perugi G, Marazziti D (1998) Prevalence of psychiatric disorders in thyroid diseased patients. Neuropsychobiology 38:222-225

11. Chueire VB, Romaldini JH, Ward LS (2007) Subclinical hypothyroidism increases the risk for depression in the elderly. Arch Gerontol Geriatr 44:21-28

12. Rinieris P, Christodoulou GN, Souvatzoglou A, Koutras DA, Stefanis C (1980) Free-thyroxine index in schizophrenic patients before and after neuroleptic treatment. Neuropsychobiology 6:29-33

13. Rao ML, Gross G, Huber G (1984) Altered interrelationship of dopamine, prolactin, thyrotropin and thyroid hormone in schizophrenic patients. Eur Arch Psychiatry Neurol Sci 234:8-12

14. Martinos A, Rinieris P, Papachristou DN, Souvatzoglou A, Koutras DA, Stefanis C (1986) Effects of six weeks' neuroleptic treatment on the pituitary-thyroid axis in schizophrenic patients. Neuropsychobiology 16:72-77

15. Rao ML, Gross G, Strebel B, Braunig P, Huber G, Klosterkotter J (1990) Serum amino acids, central monoamines, and hormones in drug-naive, drug-free, and neuroleptic-treated schizophrenic patients and healthy subjects. Psychiatry Res 34:243-257

16. Yazici K, Yazici AE, Taneli B (2002) Different neuroendocrine profiles of remitted and nonremitted schizophrenic patients. Prog Neuropsychopharmacol Biol Psychiatry 26:579-584

17. Baumgartner A, Pietzcker A, Gaebel W (2000) The hypothalamic-pituitary-thyroid axis in patients with schizophrenia. Schizophr Res 44:233-243

18. Baskin HJ, Cobin RH, Duick DS, Gharib H, Guttler RB, Kaplan MM, Segal RL (2002) American Association of Clinical Endocrinologists medical guidelines for clinical practice for the evaluation and treatment of hyperthyroidism and hypothyroidism. Endocr Pract 8:457-469
19. Baloch Z, Carayon P, Conte-Devolx B et al (2003) Laboratory medicine practice guidelines. Laboratory support for the diagnosis and monitoring of thyroid disease. Thyroid 13:3-126

20. Hollowell JG, Staehling NW, Flanders WD, Hannon WH, Gunter EW, Spencer CA, Braverman LE (2002) Serum TSH, T(4), and thyroid antibodies in the United States population (1988 to 1994): National Health and Nutrition Examination Survey (NHANES III). J Clin Endocrinol Metab 87:489-499

21. Kratzsch J, Fiedler GM, Leichtle A et al (2005) New reference intervals for thyrotropin and thyroid hormones based on National Academy of Clinical Biochemistry criteria and regular ultrasonography of the thyroid. Clin Chem 51:1480-1486

22. Garmendia Madariaga A, Santos Palacios S, Guillen-Grima F, Galofre JC (2014) The incidence and prevalence of thyroid dysfunction in Europe: a meta-analysis. J Clin Endocrinol Metab 99:jc20132409

23. Sabeen S, Chou C, Holroyd S (2010) Abnormal thyroid stimulating hormone (TSH) in psychiatric long-term care patients. Arch Gerontol Geriatr 51:6-8

24. Cole DP, Thase ME, Mallinger AG, Soares JC, Luther JF, Kupfer DJ, Frank E (2002) Slower treatment response in bipolar depression predicted by lower pretreatment thyroid function. Am J Psychiatry 159:116-121

25. Ozerdem A, Tunca Z, Cimrin D, Hidiroglu C, Ergor G (2014) Female vulnerability for thyroid function abnormality in bipolar disorder: role of lithium treatment. Bipolar Disord 16:72-82

26. Hatterer JA, Herbert J, Hidaka C, Roose SP, Gorman JM (1993) CSF transthyretin in patients with depression. Am J Psychiatry 150:813-815

27. Hennemann G, Docter R, Friesema EC, de Jong M, Krenning EP, Visser TJ (2001) Plasma membrane transport of thyroid hormones and its role in thyroid hormone metabolism and bioavailability. Endocr Rev 22:451-476

28. Eker SS, Akkaya C, Sarandol A, Cangur S, Sarandol E, Kirli S (2008) Effects of various antidepressants on serum thyroid hormone levels in patients with major depressive disorder. Prog Neuropsychopharmacol Biol Psychiatry 32:955-961

29. Magliozzi JR, Mungas D, Laubly JN, Blunden D (1989) Effect of haloperidol on a symbol digit substitution task in normal adult males. Neuropsychopharmacology 2:29-37 